\title{
Defects, Process Parameters and Signatures for Online Monitoring and Control in Powder-based Additive Manufacturing
}

\author{
Ehsan Malekipour ${ }^{1}$, Hazim El-Mounayri² \\ Collaborative Additive Manufacturing Research Initiative at IUPUI (CAMRI) \\ Purdue School of Engineering and Technology, Indianapolis, IN, USA \\ emalekip@purdue.edu', helmouna@iupui.edu ${ }^{2}$
}

\begin{abstract}
:
Additive Manufacturing (AM) is a process that is based on manufacturing parts layer by layer in order to avoid any geometric limitation in terms of creating the desired design. In the early stages of AM development, the goal was just creating some prototypes to decrease the time of manufacturing assessment. But with metal-based AM, it is now possible to produce enduse parts. In powder-based AM, a designed part can be produced directly from the STL file (Standard Tessellation Language/ stereolithography) layer by layer by exerting a laser beam on a layer of powder with thickness between $20 \mu \mathrm{m}$ to $100 \mu \mathrm{m}$ to create a section of the part. The Achilles' heel of this process is generation of some defects, which weaken the mechanical properties and in some cases, these defects may even lead to part failure under manufacturing. This prevents metal-based AM technology from spreading widely while limiting the repeatability and precision of the process. Online monitoring $(\mathrm{OM})$ and intelligent control, which has been investigated prevalently in contempororay research, presents a feasible solution to the aformentioned issues, insofar as it monitors the generated defects during the process and eliminates them in real-time. In this regard, this paper reveals the most frequent and traceable defects which significantly affect quality matrices of the produced part in powder-based AM, predominately focusing on the Selective Laser Sintering (SLS) process. These defects are classified into "Geometry and Dimensions," "Surface Quality (Finishing)," "Microstructure" and the defects leading to "Weak Mechanical Properties." In addition, we introduce and classify the most important parameters, which can be monitored and controlled to avoid those defects. Furthermore, these parameters may be employed in some error handling strategies to remove the generated defects. We also introduce some signatures that can be monitored for adjusting the parameters into their optimum value instead of monitoring the defects directly.
\end{abstract}

Keywords: Additive Manufacturing, Powder-based Additive Manufacturing, Defects and Process parameters, Online Monitoring and Control, Intelligent Control

\section{Introduction}

Additive Manufacturing (AM) is a process which is based on manufacturing parts layer by layer in order to avoid any geometric limitation in terms of creating the desired design. AM was started by producing parts using the method of stereolithography. In the early stages of AM development, the goal of AM was just creating some prototypes to decrease the time of manufacturing assessment. But with metal-based AM [1-7] it is now possible to produce end-used parts. In Selective Laser Sintering (SLS), a designed part can be produced directly from the STL ${ }^{1}$ file layer by layer by exerting a laser beam on a layer of powder with thickness between $20 \mu \mathrm{m}$ to $100 \mu \mathrm{m}$ to sinter the powder particles together to create a section of the part, the thickness of layer. The Achilles' heel of this process is generating some defects during the process which lead to the weakening of the mechanical properties for some products. In some cases these defects lead to part failure under manufacturing or during post-processing/operation. This prevents the technology from spreading widely and limits the repeatability and precision of the process. In following, we classified the defects, signatures and process parameters which can be employed in online monitoring and control.

\section{Classification of defects for online monitoring and control}

There are two main approaches to control the defects during AM process, which are described below.

The first approach uses analytical models, in order to predict the values of the process parameters [8-14]. However, there is a lack of mathematical and statistical models of and algorithms for the AM process to accurately predict process parameters in order to avoid failures, improve the part quality and produce a perfect product. These parameters are employed to account for the process specifications such as the material, ambient temperature, geometry, required speed of

\footnotetext{
${ }^{1}$ Standard Tessellation Language (stereolithography)
} 
manufacturing, scan pattern, etc. To date, all of the conducted investigations are based on simulation and physics-based Finite Element Analysis (FEA) that are complex and, introduce high computational burden [15, 16]. Efficient analytical and data driven models which are capable of processing large data streams are strongly needed for real-time control. This limitation is due to the complex nature of the sintering process due to the change in material properties as a result of increased temperature, in the plurality of contributing parameters and process parameters, and the lack of understanding of physical and chemical reactions between powders during the process. These problems encouraged scholars to consider the second approach.

The second approach is Online Monitoring (OM). The most significant advantages of this approach are: 1) It can be implemented without a full modeling of the physics of sintering phenomena; 2) It can be employed to eliminate the generated defects precisely. There is a good volume of literature on the different types of defects to improve the quality of the final produced part by adjusting the contributing parameters in the suitable range. However, there is a lack of effective/systematic classification of the defects which significantly affects quality matrices of the produced part and their contributing parameters. Also, the correlation between those defects and contributing parameters. In addition, no focus on the most important parameters which can be monitored and controlled to avoid those defects; the literature, however, shows some primary grouping of parameters [7].

As it is shown in Figure 1, we classified 13 different defects related to "Geometry and Dimensions", "Surface Quality (Finishing)", "Microstructure" and the defects behind "Weak Mechanical Properties".

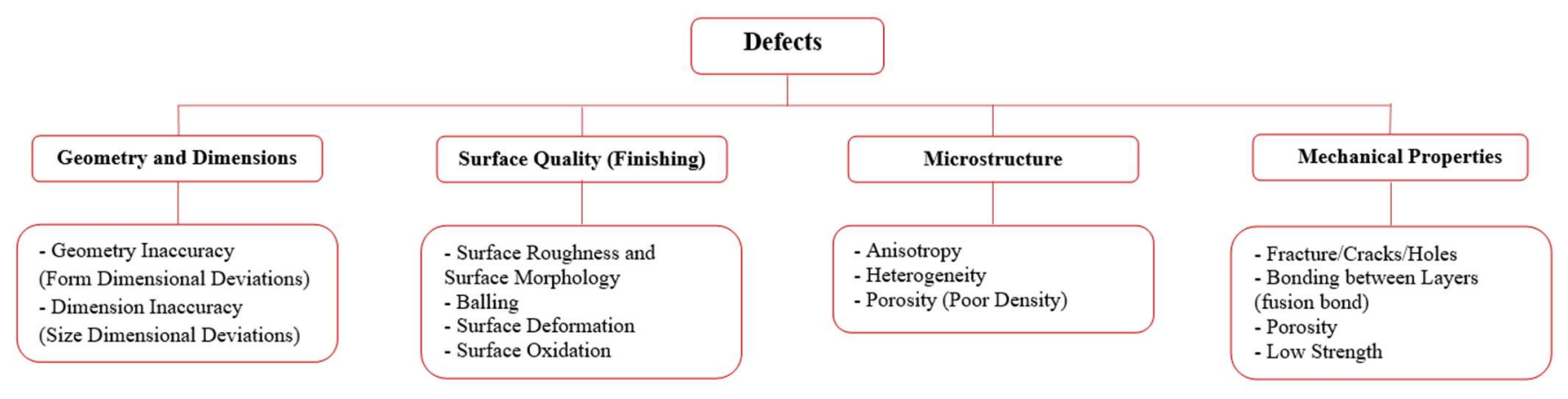

Figure 1: Common defects in SLS process

From online monitoring point of view, we can reorganize all the mentioned defects under a quintuple set of manufacturing features revealed here. If we can monitor and control this set of features, achieving in flawless part will be applicable [17-24].

\section{The homogeneous deposition of the powder}

As it is already mentioned uniformly Powder deposition, smoothness of every deposited powder layer and uniform spreading are very curtail for surface quality.

\section{Thermal characteristics of the layer under fabrication}

Temperature characteristics such as homogeneous temperature distribution, heat accumulation in different zones, etc. is an excellent proxy [25] in order to attain the best possible homogenous microstructure which directly effect on mechanical properties as one of the most important demands in SLS manufacturing.

3. Surface quality related defects for a single layer

It includes a vast number of defects such as cracks, holes, etc. It is noteworthy that some of the defects such as porosity needs to be checked after every specific number of layers. [26-28]

4. Improper part geometry and dimension inaccuracy:

This is the most important category regarding repeatability. As explained in section 1 defects such as shrinkage leads to some inaccuracy geometrically and dimensionally. [26]

5. Poor bonding between the layers:

It is very effective on the mechanical properties and mainly affected by energy density, penetration depth and layer thickness. $[28,29]$ 
Also, it has been turned out that all of these defects/features can be handled by just a small set of controllable parameters. In other words, by controlling those few parameters, vendors can prevent defects in some cases or eliminate them in some other cases, after detecting, and as a result, reach the best possible quality for the fabricated part [18],[30-32]. These parameters are derived, classified and explained in the following section. It also should be noticed that, all of these fields are able to be monitored by current instruments and there are numerous approaches which are introduced in literature to monitor some of these defects/features. [33-36] [37-44]

\section{Classification of process parameters for online monitoring and control}

Nowadays, the parts produced in SLS are used as end-used products. Therefore, producing a part with perfect homogeneous microstructure and exclusive defects is considered as ultimate objective of SLS process. In this regard, there are some barriers, challenges and gaps including powder properties knowledge, chain capabilities measurement science, standardization, monitoring defects and control manufacturing process. "Energetics Incorporated" addressed these items and prepared a road map for NIST to show the gaps needed to be filled [45]. Online monitoring and process control as an ongoing discussion can help to develop this process significantly. In this context, there are various defects, signatures and parameters affecting the quality of a printed part and its microstructure which can be controlled by aligning process parameters with optimized values through online monitoring. Hence, it is crucial to utilize some techniques to monitor and control process parameters and probably, desired signatures constantly in order to avoid the defects. To further establish a thorough procedure for the monitoring and controller strategy, the process parameters can be classified into three categories as shown in Figure 2. As this figure depicts, the first category is "pre-processed parameters" which should be specified before starting the process. This category is divided into two subcategories itself. The first one, the "pre-defined parameters", includes the items which must be chosen or set before the manufacturing process. There is an optimum value or a best state to be chosen for each of them. It is noteworthy that these parameters are constant for any SLS process regardless of the manufactured part. Consequently, vendors will not need to monitor or control them. This category mostly include powder specifications and machine specifications.

The second subcategory, the "Pre-defined parameters that need to be monitored", includes the parameters inside the chamber as well as machine error parameters. These parameters must be specified before starting the manufacturing process as well, but they can be changed during the process; however, these changes are undesirable and thus, need to be monitored and kept constant. It is important to note that unlike the first group of parameters, they may have a different optimum value or state, based on the chosen material. To sum up, we would need to monitor them in situ to keep them fix but we would not need to control them to alter their values during the process.

The second category of parameters are the most important parameters for online monitoring in SLS process. This category which is called "controllable parameters" includes process parameters (laser specifications and scan strategy) and manufacturing specifications. These parameters need to be monitored and altered in situ based on: 1) the feedback that controller received from the sensors to adjust these parameters with the benchmarks information; 2) manufacturing strategy such as laser pattern; and 3) the chosen manufacturing preference such as time of manufacturing, desired mechanical properties, density, etc. It should be noted that currently all of these parameters are pre-defined and constant during the manufacturing process; however, the manufacturers can assign the correct value or choose the suitable state of process parameters based on the mentioned items. There are two main reasons why these parameters should be monitored and controlled. The first reason is to avoid as much defects as possible and reach the best possible end-used part. For instance, one recommended potential application is altering the pace of manufacturing by using thicker layer in parts with perpendicular walls to the base plate. In this case we would need to adjust other parameters such as laser power or laser speed to keep strong bonding between layers. It should be noted that all of these parameters can be easily measured and controlled by the machine.

The second reason is to eliminate the defects after their detection when possible. Actually, defects are created due to some manufacturing uncertainty such as the imprecision of the process, stochastic spreading of powders, the inability to predict and choose the most suitable process parameters, etc. The reason is that, there is no analytical model that can be used reliably for prediction and explain the process completely [25] 


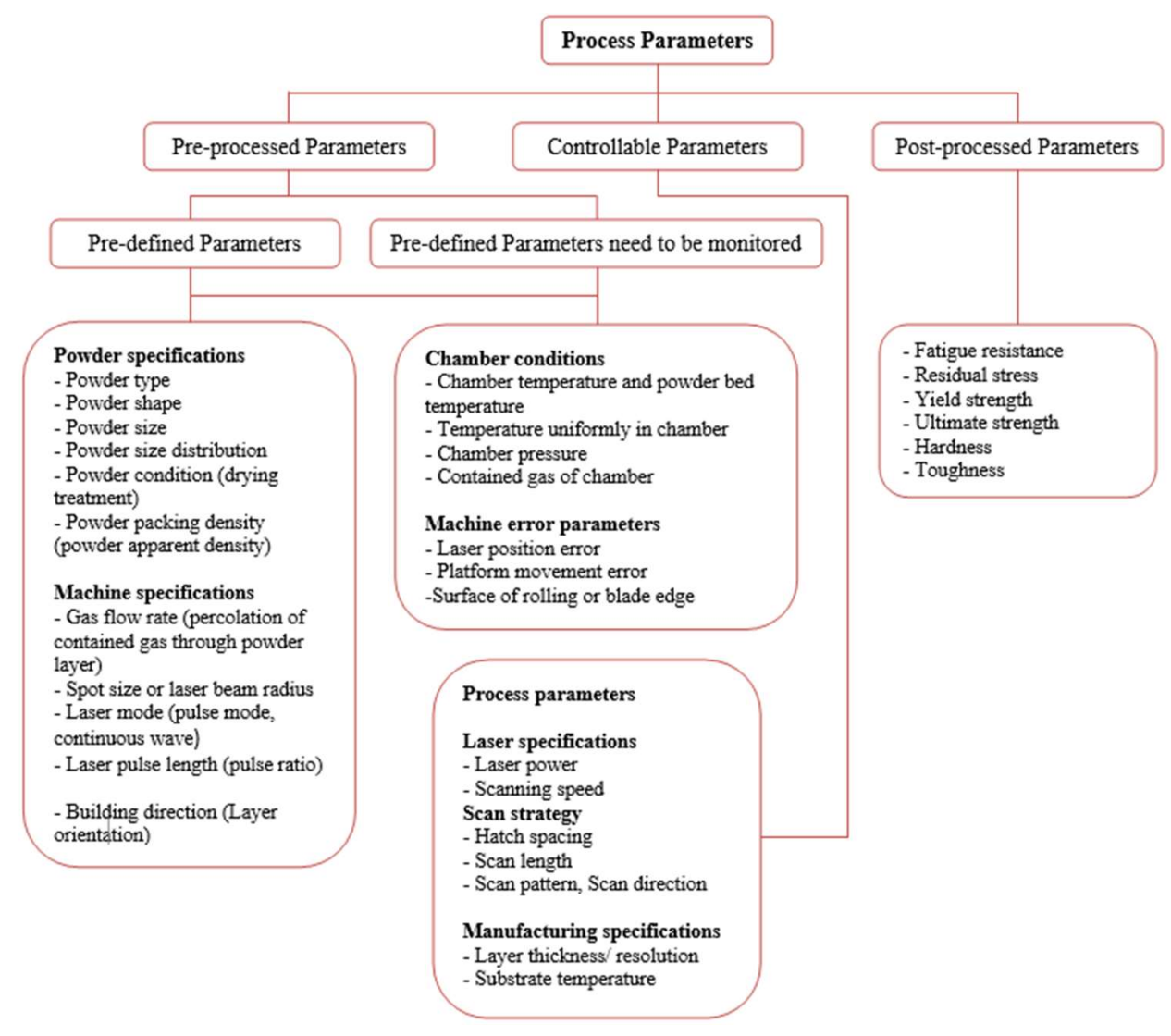

Figure 2: Process parameters classification

The final category is post-process parameters witch are not possible to be monitored during the process. These parameters such as yield strength, ultimate strength, etc. showing the mechanical properties of the manufactured part, are among the most desired demands of manufacturing and they are affected by microstructures defects and grain structures, For example, micro crack can lead to stress concentration which reduces life time in fatigue condition. [46] We can improve the mechanical properties by controlling the contributing parameters affecting microstructure. At the very end of the process, these parameters show the quality of the manufacturing process and the success rate of online monitoring approach.

Table 1 shows how contributing parameters affect the defects or process features (effected items) in powder-based AM process. As it reveals, there are only five parameters which need to be monitored and kept fixed (second category) and 10 parameters which need to be monitored and controlled (third category). These parameters are recommended for online monitoring and control of powder-based process specifically for SLS process.

Table 1: Parameter classification using for online monitoring in SLS process

\begin{tabular}{lll}
\hline No. & Process Parameter & Effected items \\
\hline First category: predefined parameters & \\
\hline $\mathbf{1}$ & Powder shape & $\begin{array}{l}\text { Surface contamination, flowability of bulk of powder (smooth } \\
\text { deposition), powder packing density and powder apparent density, } \\
\text { porosity, powder fluidity }\end{array}$ \\
\hline $\mathbf{2}$ & Powder size & $\begin{array}{l}\text { Flowability of bulk of powder, balling, powder packing density and } \\
\text { powder apparent density, material strength, oxidation, layer thickness }\end{array}$ \\
\hline $\mathbf{3}$ & Powder size distribution & powder packing density and powder apparent density \\
\hline $\mathbf{4}$ & Powder condition/ drying treatment & Balling, heterogeneity, porosity, oxidation \\
\hline $\mathbf{5}$ & $\begin{array}{l}\text { Powder packing density/ Powder } \\
\text { apparent density }\end{array}$ & Porosity/ density \\
\hline $\mathbf{6}$ & Gas flow (rate and direction) & Dimensional tolerance, bonding between layers \\
\hline $\mathbf{7}$ & Building direction (Layer orientation) & Dimension inaccuracy, anisotropy, porosity, mechanical properties \\
\hline
\end{tabular}

(C) The Society of Experimental Mechanics, Inc. 2018

Mechanics of Additive and Advanced Manufacturing, Volume 9 


\begin{tabular}{|c|c|c|}
\hline 8 & Spot diameter and beam radius & $\begin{array}{l}\text { Dimension inaccuracy, surface roughness, porosity (penetration } \\
\text { energy density and energy absorption }\end{array}$ \\
\hline 9 & $\begin{array}{l}\text { Laser mode (pulse mode, continuous } \\
\text { wave) }\end{array}$ & Porosity (density), balling (wetting angle) \\
\hline 10 & Laser pulse length/ pulse ratio & Surface roughness, bonding between layers \\
\hline \multicolumn{3}{|c|}{ Second category: predefined parameters that need to be monitored } \\
\hline 11 & $\begin{array}{l}\text { Chamber temperature and powder } \\
\text { bed temperature (workpiece } \\
\text { temperature) }\end{array}$ & Shrinkage, heterogeneity, surface deformation, absorptivity \\
\hline 12 & Gas flow rate & $\begin{array}{l}\text { Dimensional inaccuracy, porosity, mechanical properties, } \\
\text { bonding between layers }\end{array}$ \\
\hline 13 & Contained gas of chamber & Balling, oxidation \\
\hline 14 & $\begin{array}{l}\text { Percolation of contained gas through } \\
\text { powder layer }\end{array}$ & Surface oxidation \\
\hline \multicolumn{3}{|c|}{ Third category: parameters should be monitored and controlled } \\
\hline 15 & Laser power & $\begin{array}{l}\text { Shrinkage, balling (energy density), warping, layer distortion, } \\
\text { porosity, melt pool size and morphology, penetration depth }\end{array}$ \\
\hline 16 & Scanning speed & $\begin{array}{l}\text { Shrinkage, surface roughness, balling (energy density, poor } \\
\text { wetting), layer distortion, porosity, melt pool size and } \\
\text { morphology, fracture/cracks/holes }\end{array}$ \\
\hline 17 & Laser positioning error & Geometry inaccuracy \\
\hline 18 & Hatch Spacing & $\begin{array}{l}\text { Shrinkage, surface roughness, energy density, heterogeneity, } \\
\text { porosity, melt pool size and morphology, dimension } \\
\text { inaccuracy (microstructural waviness), surface deformation } \\
\text { (heat accumulation) }\end{array}$ \\
\hline 19 & Scan length & Shrinkage, warping, fracture/cracks/holes \\
\hline 20 & Scan pattern, Scan direction & Surface roughness, porosity/ density, heterogeneity, anisotropy \\
\hline 21 & Platform movement error & Geometry inaccuracy \\
\hline 22 & Layer thickness/ resolution & $\begin{array}{l}\text { Staircase effect, shrinkage, energy density, porosity/density, } \\
\text { bonding between layers/ penetration depth, construction speed }\end{array}$ \\
\hline 23 & Blade edge or surface of rolling & Pit on the surface, powder deposition/ distribution \\
\hline 24 & Substrate temperature & Balling, distortion and warpage, poor wetting, melt pool shape \\
\hline
\end{tabular}

\section{Using of signatures in online process control}

Another way to perform monitoring in SLS or other AM processes is to monitor and measure some signatures instead of monitoring defects and parameters directly. Signatures are defined as some manufacturing specifications or combination of some parameters which may be utilized to adjust the controllable parameters to avoid the defects. We can divide Signatures into two different types: The first type can be defined as "Manufacture Signature". This type of signatures are the manufacturing specifications which are affected clearly by the controllable parameters and hence, this correlation may be utilized to adjust the controllable parameters. It should be noted that all of these Manufacture Signature relate to melting phenomena and melt poll specification. [19], [47-50] Thus, they are suitable to be used in SLM process. The second type of signature can be defined as "Cumulative Signature" which consists of number of controllable parameters which are able to be set according to some prepared benchmark. These parameters can be used for both SLM and SLS process [18, 34, 51]. The melt pool specifications, Marangoni convection and a feature set of laser scan are recommended in literature (or here for the first time) to be used as signatures in monitoring approaches. The detailed explanation about the correlation between these items and their contributing parameters was mentioned in section 2.

\subsection{Manufacturing signature (for SLM process)}

\subsubsection{Melt pool morphology and melt pool dimensions}

Melt pool morphology (and as a result melt pool dimension including melt pool depth) has a strong effect on the bonding between scan tracks and as a result, inter-run porosity and final density, balling, Heat Affected Zone (HAZ), penetration depth and porosity [52-54]. In HAZ area the dimensions of melt pool grow because of lack of heat conductivity and thus, the surface quality declines significantly. As it is revealed in reference [34], generating support structure can reinforce these areas while improve heat conductivity which leads to better surface quality. The parameters contributed in melt pool morphology 
are scan speed, laser power, spot size, the type of powder, overlapping ratio and the number of laser scan. We can also map the melt pool dimensions with the generated microstructure to indirectly control solidification microstructure. [55, 56]

\subsubsection{Melt pool temperature and solidification rate}

Melt pool temperature, solidification rate, temperature gradient and scan speed are closely related to each other and significantly affect solidification microstructure, homogeneity, and type of grain structure (cellular or dendritic). The governing equation is

$$
\frac{\mathrm{G}}{\mathrm{R}}=\frac{\mathrm{T}_{\mathrm{p}}}{\mathrm{ux}_{1}}
$$

Where $T_{p}$ is melt pool temperature, $\mathrm{u}$ is scan speed, $x_{1}$ is distance between the heat source and the rear of the weld pool, $\mathrm{G}$ is temperature gradient and $\mathrm{R}$ is solidification velocity. Furthermore, melt pool temperature affects melt pool depth whose correlation is shown Figure 3; the solidification rate affects porosity (with entrapping gas), shrinkage, balling and melt pool geometry.

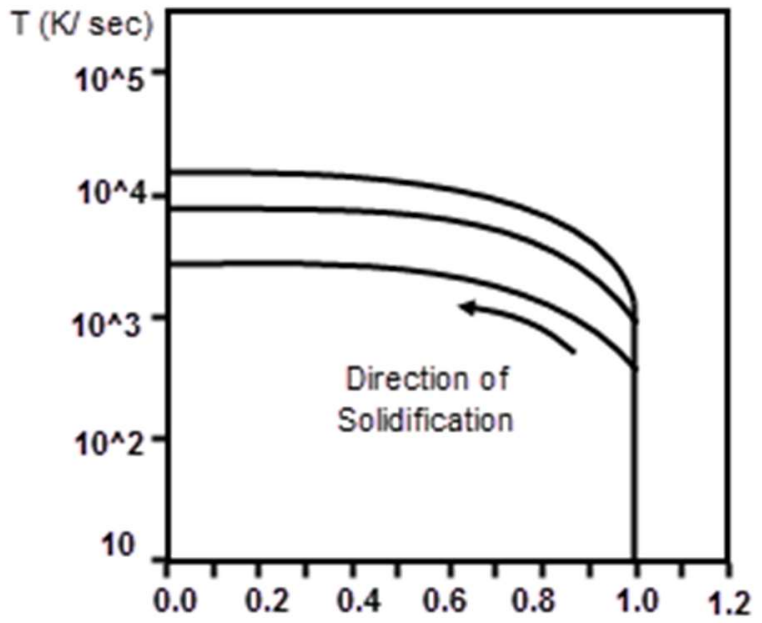

Figure 3: Dependence T vs. dimensionless melt depth at different scan speed

\subsubsection{Marangoni convection (MC)}

Altering the temperature coefficient of surface tension (due to variation of the solute oxygen) and generating large thermal gradient between the center and edge of the melt pool (due to the use of laser Gaussian distribution) leads to surface tension gradient. This tension gradient triggers fluid flow in melt pool causing changes in temperature gradient. This phenomena, called $\mathrm{MC}$, changes the melt penetration, generates deep narrow tracks (leading to inter-run porosity), changes bonding between layers, the ratio of depth/width of melt pool and the melt pool morphology (cross section of melt pool). Balling, humping, changes surface morphology, solidification microstructure and warping are other effected items. [12, 52, 57]

\subsection{Cumulative signature (for SLS and SLM)}

Overlapping ratio and energy density (energy input) can be introduced as cumulative signatures. Overlapping ratio affects surface roughness, porosity and melt penetration. Energy density however can effect on balling, heterogeneity/homogeneity, density (porosity), melt pool size, and melt pool morphology, wetting angle and solidification.

\section{Conclusion and future works}

This paper reveals the most common defects in SLS process and also, classifies the defects addressed by literatures as the most prevalent defects in five categories to use for monitoring purposes. It also classifies process parameters in pre-defined, 
controllable and post-process ones and recommends to set the controllable parameters on their optimized values in situ to avoid the defects.

This paper also elaborates on the concept of signatures and introduces some potential signatures which can be employed in order to control the quality of the fabricated parts indirectly.

It is noteworthy that however literatures introduced a set of efficient approaches to monitor some of these defects/signatures, there is no integrated approach to cover all the defects and also, there is no impressive approaches to eliminate the detected defects efficiently.

\section{References}

[1] W. E. Frazier, "Metal additive manufacturing: a review," Journal of Materials Engineering and Performance, vol. 23, pp. 1917-1928, 2014.

[2] J. Ruan, T. E. Sparks, Z. Fan, J. K. Stroble, A. Panackal, and F. Liou, "A review of layer based manufacturing processes for metals," in 17th Solid Freeform Fabrication Symposium, Austin (USA), 2006, pp. 233-245.

[3] K. V. Wong and A. Hernandez, "A review of additive manufacturing," ISRN Mechanical Engineering, vol. 2012, 2012.

[4] P. Kulkarni, A. Marsan, and D. Dutta, "A review of process planning techniques in layered manufacturing," Rapid Prototyping Journal, vol. 6, pp. 18-35, 2000.

[5] D. Gu, W. Meiners, K. Wissenbach, and R. Poprawe, "Laser additive manufacturing of metallic components: materials, processes and mechanisms," International materials reviews, vol. 57, pp. 133164, 2012.

[6] V. Bhavar, P. Kattire, V. Patil, S. Khot, K. Gujar, and R. Singh, "A Review on Powder Bed Fusion Technology of Metal Additive Manufacturing," in International Conference \& Exhibition on Additive Manufacturing Technologies Bangalore, India, 2015.

[7] X. Gong, T. Anderson, and K. Chou, "Review on powder-based electron beam additive manufacturing technology," in ASME/ISCIE 2012 international symposium on flexible automation, 2012, pp. 507-515.

[8] A. Flood and F. Liou, "Modeling of Powder Bed Processing-A Review," in International Solid Freeform Fabrication Symposium, 2015.

[9] R. Ganeriwala and T. I. Zohdi, "Multiphysics modeling and simulation of selective laser sintering manufacturing processes," Procedia CIRP, vol. 14, pp. 299-304, 2014.

[10] T. I. Zohdi, "Rapid simulation of laser processing of discrete particulate materials," Archives of Computational Methods in Engineering, vol. 20, pp. 309-325, 2013.

[11] B. Xiao and Y. Zhang, "Laser sintering of metal powders on top of sintered layers under multiple-line laser scanning," Journal of Physics D: Applied Physics, vol. 40, p. 6725, 2007.

[12] B. Xiao and Y. Zhang, "Marangoni and buoyancy effects on direct metal laser sintering with a moving laser beam," Numerical Heat Transfer, Part A: Applications, vol. 51, pp. 715-733, 2007.

[13] K. Zeng, D. Pal, and B. Stucker, "A review of thermal analysis methods in laser sintering and selective laser melting," in Proceedings of Solid Freeform Fabrication Symposium Austin, TX, 2012.

[14] E. Attar, "Simulation of selective electron beam melting processes," Dr.-Ing., University of Erlangen, Nuremberg, Germany, 2011.

[15] N. N'Dri, H. W. Mindt, B. Shula, M. Megahed, A. Peralta, P. Kantzos, et al., "DMLS process modelling \& validation," TMS2015 Supplemental Proceedings, pp. 389-396, 2015.

[16] W. King, A. Anderson, R. Ferencz, N. Hodge, C. Kamath, and S. Khairallah, "Overview of modelling and simulation of metal powder bed fusion process at Lawrence Livermore National Laboratory," Materials Science and Technology, vol. 31, pp. 957-968, 2015.

[17] A. Spierings, N. Herres, and G. Levy, "Influence of the particle size distribution on surface quality and mechanical properties in AM steel parts," Rapid Prototyping Journal, vol. 17, pp. 195-202, 2011.

[18] T. Craeghs, F. Bechmann, S. Berumen, and J.-P. Kruth, "Feedback control of Layerwise Laser Melting using optical sensors," Physics Procedia, vol. 5, pp. 505-514, 2010. 
[19] T. Craeghs, S. Clijsters, E. Yasa, and J.-P. Kruth, "Online quality control of selective laser melting," in Proceedings of the Solid Freeform Fabrication Symposium, Austin, TX, 2011, pp. 212-226.

[20] D. Hu and R. Kovacevic, "Sensing, modeling and control for laser-based additive manufacturing," International Journal of Machine Tools and Manufacture, vol. 43, pp. 51-60, 2003.

[21] D. Hu, H. Mei, and R. Kovacevic, "Improving solid freeform fabrication by laser-based additive manufacturing," Proceedings of the Institution of Mechanical Engineers, Part B: Journal of Engineering Manufacture, vol. 216, pp. 1253-1264, 2002.

[22] M. Mahesh, Y. Wong, J. Fuh, and H. Loh, "A six-sigma approach for benchmarking of RP\&M processes," The International Journal of Advanced Manufacturing Technology, vol. 31, pp. 374-387, 2006.

[23] R. Paul and S. Anand, "Process energy analysis and optimization in selective laser sintering," Journal of Manufacturing Systems, vol. 31, pp. 429-437, 2012.

[24] M. Khaing, J. Fuh, and L. Lu, "Direct metal laser sintering for rapid tooling: processing and characterisation of EOS parts," Journal of Materials Processing Technology, vol. 113, pp. 269-272, 2001.

[25] G. Tapia and A. Elwany, "A review on process monitoring and control in metal-based additive manufacturing," Journal of Manufacturing Science and Engineering, vol. 136, p. 060801, 2014.

[26] J. Delgado, J. Ciurana, and C. A. Rodríguez, "Influence of process parameters on part quality and mechanical properties for DMLS and SLM with iron-based materials," The International Journal of Advanced Manufacturing Technology, vol. 60, pp. 601-610, 2012.

[27] E. Yasa, J. Deckers, T. Craeghs, M. Badrossamay, and J.-P. Kruth, "Investigation on occurrence of elevated edges in selective laser melting," in International Solid Freeform Fabrication Symposium, Austin, TX, USA, 2009, pp. 673-85.

[28] H. Meier and C. Haberland, "Experimental studies on selective laser melting of metallic parts," Materialwissenschaft und Werkstofftechnik, vol. 39, pp. 665-670, 2008.

[29] K. Abd-Elghany and D. Bourell, "Property evaluation of 304L stainless steel fabricated by selective laser melting," Rapid Prototyping Journal, vol. 18, pp. 420-428, 2012.

[30] S. Berumen, F. Bechmann, S. Lindner, J.-P. Kruth, and T. Craeghs, "Quality control of laser-and powder bed-based Additive Manufacturing (AM) technologies," Physics procedia, vol. 5, pp. 617-622, 2010.

[31] I. Llanos, A. Agirre, I. Quintana, and H. Urreta, "Defect elimination on laser milled geometries by means of error detection and correction," The International Journal of Advanced Manufacturing Technology, pp. 1-8, 2015.

[32] A. Verma, S. Tyagi, and K. Yang, "Modeling and optimization of direct metal laser sintering process," The International Journal of Advanced Manufacturing Technology, vol. 77, pp. 847-860, 2015.

[33] S. Kleszczynski, J. Zur Jacobsmühlen, J. Sehrt, and G. Witt, "Error detection in laser beam melting systems by high resolution imaging," in Proceedings of the Solid Freeform Fabrication Symposium, 2012.

[34] T. Craeghs, S. Clijsters, J.-P. Kruth, F. Bechmann, and M.-C. Ebert, "Detection of process failures in layerwise laser melting with optical process monitoring," Physics Procedia, vol. 39, pp. 753-759, 2012.

[35] Y. Chivel and I. Smurov, "On-line temperature monitoring in selective laser sintering/melting," Physics Procedia, vol. 5, pp. 515-521, 2010.

[36] P. Lott, H. Schleifenbaum, W. Meiners, K. Wissenbach, C. Hinke, and J. Bültmann, "Design of an optical system for the in situ process monitoring of selective laser melting (SLM)," Physics Procedia, vol. 12, pp. 683-690, 2011.

[37] I. Yadroitsev, P. Krakhmalev, and I. Yadroitsava, "Selective laser melting of Ti6Al4V alloy for biomedical applications: Temperature monitoring and microstructural evolution," Journal of Alloys and Compounds, vol. 583, pp. 404-409, 2014.

[38] R. B. Dinwiddie, R. R. Dehoff, P. D. Lloyd, L. E. Lowe, and J. B. Ulrich, "Thermographic in-situ process monitoring of the electron-beam melting technology used in additive manufacturing," in SPIE Defense, Security, and Sensing, 2013, pp. 87050K-87050K-9. 
[39] S. Price, J. Lydon, K. Cooper, and K. Chou, "Experimental temperature analysis of powder-based electron beam additive manufacturing," in Proceedings of the Solid Freeform Fabrication Symposium, 2013, pp. 162-173.

[40] E. Rodriguez, F. Medina, D. Espalin, C. Terrazas, D. Muse, C. Henry, et al., "Integration of a thermal imaging feedback control system in electron beam melting," in Proceedings of the Solid Freeform Fabrication Symposium, 2012.

[41] A. Wegner and G. Witt, "Process monitoring in laser sintering using thermal imaging," in SFF Symposium, Austin, Texas, USA, 2011, pp. 8-10.

[42] H. Krauss, C. Eschey, and M. Zaeh, "Thermography for monitoring the selective laser melting process," in Proceedings of the Solid Freeform Fabrication Symposium, 2012.

[43] S. Santospirito, K. Słyk, B. Luo, R. Łopatka, O. Gilmour, and J. Rudlin, "Detection of defects in laser powder deposition (LPD) components by pulsed laser transient thermography," in SPIE Defense, Security, and Sensing, 2013, pp. 87050X-87050X-11.

[44] S. Price, K. Cooper, and K. Chou, "Evaluations of temperature measurements by near-infrared thermography in powder-based electron-beam additive manufacturing," in Proceedings of the Solid Freeform Fabrication Symposium, 2012, pp. 761-773.

[45] S. Kerwien, S. Collings, F. Liou, and M. Bytnar, "Measurement Science Roadmap for Metal-based Additive Manufacturing," ed: NIST, 2013.

[46] F. Ellyin, Fatigue damage, crack growth and life prediction: Springer Science \& Business Media, 2012.

[47] P. Aggarangsi, J. L. Beuth, and M. Griffith, "Melt pool size and stress control for laser-based deposition near a free edge," in Solid Freeform Fabrication Proceedings, 2003, pp. 196-207.

[48] P. Aggarangsi, J. L. Beuth, and D. D. Gill, "Transient changes in melt pool size in laser additive manufacturing processes," in Solid Freeform Fabrication Proceedings, University of Texas, Solid Freeform Fabrication Symposium, Austin, TX, Aug, 2004, pp. 2-4.

[49] A. Birnbaum, P. Aggarangsi, and J. Beuth, "Process scaling and transient melt pool size control in laserbased additive manufacturing processes," in Solid Freeform Fabrication Proceedings, 2003, pp. 328-339.

[50] M. R. Boddu, R. G. Landers, and F. W. Liou, "Control of laser cladding for rapid prototyping-A review," in Proceedings of the Solid Freeform Fabrication Symposium, 2001, pp. 6-8.

[51] G. Bi, A. Gasser, K. Wissenbach, A. Drenker, and R. Poprawe, "Characterization of the process control for the direct laser metallic powder deposition," Surface and Coatings Technology, vol. 201, pp. 2676-2683, 2006.

[52] C. Hauser, "Selective laser sintering of a stainless steel powder," University of Leeds, 2003.

[53] H. Gong, H. Gu, K. Zeng, J. Dilip, D. Pal, B. Stucker, et al., "Melt pool characterization for selective laser melting of Ti-6Al-4V pre-alloyed powder," in Solid Freeform Fabrication Proceedings, 2014.

[54] T. Scharowsky, F. Osmanlic, R. Singer, and C. Körner, "Melt pool dynamics during selective electron beam melting," Applied Physics A, vol. 114, pp. 1303-1307, 2014.

[55] B. Cheng and K. Chou, "Melt pool geometry simulations for powder-based electron beam additive manufacturing," in 24th Annual International Solid Freeform Fabrication Symposium-An Additive Manufacturing Conference, Austin, TX, USA, 2013.

[56] J. Gockel, J. Beuth, and K. Taminger, "Integrated control of solidification microstructure and melt pool dimensions in electron beam wire feed additive manufacturing of Ti-6Al-4V," Additive Manufacturing, vol. 1, pp. 119-126, 2014.

[57] D. Gu and Y. Shen, "Effects of processing parameters on consolidation and microstructure of W-Cu components by DMLS," Journal of Alloys and Compounds, vol. 473, pp. 107-115, 2009. 